\title{
Copper removal ability by Streptomyces strains with dissimilar growth patterns and endowed with cupric reductase activity
}

\author{
Virginia Helena Albarracín ${ }^{1,2}$, Ana Lucía Ávila ${ }^{1,2}$, María Julia Amoroso ${ }^{1,3}$ \& Carlos Mauricio Abate ${ }^{1,2,3}$ \\ ${ }^{1}$ Pilot Plant of Industrial and Microbiological Processes (PROIMI), CONICET, Tucumán, Argentina; ${ }^{2}$ Natural Sciences College and Miguel Lillo Institute, \\ National University of Tucumán, Tucumán, Argentina; and ${ }^{3}$ Biochemistry, Chemistry and Pharmacy College, National University of Tucumán, Tucumán, \\ Argentina
}

\begin{abstract}
Correspondence: Carlos Mauricio Abate, Pilot Plant of Industrial and Microbiological Processes (PROIMI), CONICET, Av. Belgrano y Pasaje Caseros, 4000 Tucumán, Argentina. Tel.: +54 381 4344888; fax: +54381 4344887; e-mail: cabate@proimi.org.ar
\end{abstract}

Received 8 May 2008; accepted 29 July 2008

DOI:10.1111/j.1574-6968.2008.01335.x

Editor: Clive Edwards

Keywords

copper; Actinobacteria; Streptomyces; cupric reductase; bioremediation.

\begin{abstract}
Morphological, physiological and molecular characterization of three copperresistant actinobacterial strains (AB2A, $\mathrm{AB} 3$ and $\mathrm{AB} 5 \mathrm{~A}$ ) isolated from copperpolluted sediments of a drainage channel showed that they belonged to the genus Streptomyces. These characteristics plus their distinctive copper resistance phenotypes revealed considerable divergence among the isolates. Highly dissimilar growth patterns and copper removal efficiency were observed for the selected Streptomyces strains grown on minimal medium (MM) added with $0.5 \mathrm{mM}$ of copper sulfate $\left(\mathrm{MM}_{\mathrm{Cu}}\right)$. Strain AB2A showed an early mechanism of copper uptake/retention ( $80 \%$ until day 3 ), followed by a drastic metal efflux process (days 5-7). In contrast, Streptomyces sp. AB3 and AB5A showed only copper retention phenotypes under the same culture conditions. Particularly, Streptomyces sp. AB5A showed a better efficiency in copper removal (94\%), although a longer lag phase was observed for this microorganism grown for 7 days in $\mathrm{MM}_{\mathrm{Cu}}$. Cupric reductase activity was detected in both copper-adapted cells and nonadapted cells of all three strains but this activity was up to 100 -fold higher in preadapted cells of Streptomyces sp. AB2A. To our knowledge, this is the first time that cupric reductase activity was demonstrated in Streptomyces strains.
\end{abstract}

\section{Introduction}

Copper is an essential micronutrient for both eukaryotes and prokaryotes. The biological functions of copper are closely related to its properties as a transition metal. Copper has partially filled $d$ orbitals and has more than one stable valence state, $\mathrm{Cu}(\mathrm{I})$ being a $\left(d^{10}\right)$ cation and $\mathrm{Cu}$ (II) being a $\left(d^{9}\right)$ cation. As the strongest Lewis acid in Group IB, copper has the ability to mediate electron transport, accepting and donating electrons used by metalloenzymes such as cytochrome $c$ oxidase, lysyl oxidase or superoxide dismutase (Solioz \& Stoyanov, 2003). On the other hand, copper toxicity could occur via the production of hydroxyl radicals in a Fenton-type reaction (Solioz \& Stoyanov, 2003).

Mining and industrial activities in the province of Tucumán, Argentina have led to large-scale contamination of the environment with copper (Albarracín et al., 2005). Copper tends to accumulate in soils, plants and animals, increasing their concentration and harmful effects within superior levels of food chains (Georgopoulus et al., 2002).

The screening and characterization of copper-resistant microorganisms is important in developing novel copper bioremediation processes (Albarracín et al., 2005). Microbial molecular mechanisms involved in the heavy metal resistance have been grouped to four categories: (1) highspecificity efflux transporters that spell the unwanted metal, (2) intracellular compartmenting, (3) metal chelating to form nontoxic intracellular storage compounds, and (4) extracellular chelating (cell wall, exopolymers) and detoxification (for a review see Silver \& Phung, 1996).

Metal-resistant Actinobacteria, and their potential use for bioremediation strategies, have been described before (Ravel et al., 1998; Amoroso et al., 2001; Albarracín et al., 2005, 2008; Kothe et al., 2005; Schmidt et al., 2005; Polti et al., 2007). Among the soil filamentous Actinobacteria, streptomycetes represent up to $20 \%$ of soil bacteria (Kothe et al., 2005). They are predominantly found in soil as spores, 
which are resistant to desiccation and starvation, but can germinate and grow into a mycelial state for brief periods of time when nutrients became available. Streptomycetes are recognized for their ability to produce a wide variety of secondary metabolites such as pigments, geosmine and over $80 \%$ of known antibiotics, which makes them a good source of heavy metal-binding substances with potential biotechnological application (Kothe et al., 2005). High cadmium, nickel, chromium, mercury, copper and lead resistance levels were found in several Streptomyces strains (Abbas \& Edwards, 1990; Ravel et al., 1998; Amoroso et al., 2001; Albarracín et al., 2005; Kothe et al. 2005; Schmidt et al., 2005; Polti et al., 2007) by performing an agar media test. Nevertheless, well-documented copper sequestration ability is needed to apply these strains for copper immobilization processes in successful bioremediation technologies.

In a previous screening program, three copper-resistant Actinobacteria were isolated from polluted sediments of a drainage channel at Ranchillos, in Tucumán, Argentina (Albarracín et al., 2005); they were named AB2A, AB3 and AB5A strains. The aim of this work was to perform a morphological, physiological and molecular characterization of these strains, and to study their growth behavior under copper stress conditions, their copper retention ability and the presence of cupric reductase activity.

\section{Materials and methods}

\section{Strains}

Actinomycete strains AB2A, AB3 and AB5A (PROIMI Actinomycete Collection) isolated previously from copperpolluted sediments (Albarracín et al., 2005) were used in this study.

\section{Phenotypic characterization}

For the morphological assays, the strains were grown for 10 days at $30^{\circ} \mathrm{C}$ on agar media as described by Shirling \& Gottlieb (1966): yeast extract/malt extract agar (ISP 2), oatmeal agar (ISP 3), inorganic salt/starch agar (ISP 4), glycerol/asparagine agar (ISP 5), peptone/yeast extract/iron agar (ISP 6) and tyrosine agar (ISP 7). For scanning electron microscopy, the strains were grown on ISP 2 agar over a period of 10 days (Wink et al., 2003) and then visualized using a JEOL JSM 35 CF. Utilization of carbohydrates was investigated on a mineral basal agar medium using a 12-well microtiter plate technique (Wink et al., 2003). Sodium chloride tolerance and lysozyme resistance were tested using six-well microtiter plates with casein-yeast extract-agar medium (Wink et al., 2003). The profile of enzymatic activities was obtained using the API 20E and API CORYNE test strips (Biomerieux). The production of melanin pigment was tested by growing the strains on tyrosine agar (ISP 7).

\section{DNA purification}

For DNA preparation, $\mathrm{AB} 2 \mathrm{~A}, \mathrm{AB} 3$ and $\mathrm{AB} 5 \mathrm{~A}$ strains were grown on ISP 2 broth for 4 days. The pellets were collected by centrifugation at $3000 \mathrm{~g}$ for $10 \mathrm{~min}$ at $4{ }^{\circ} \mathrm{C}$ and washed twice with distilled water. Total genomic DNA extraction was carried out according to the lysozyme treatment modified for Actinobacteria as described previously (Albarracín et al., 2004).

\section{PCR amplification and sequencing}

For taxonomic identification, PCR amplifications were performed in $25-\mu \mathrm{L}$ reaction volume using universal $16 \mathrm{~S}$ rRNA gene oligonucleotide primers: 27f and 1492r (Heuer et al., 1997) or gyrB primers (Calcutt, 1994; Yamamoto \& Harayama, 1995) in an automated thermal cycler (PerkinElmer, model 9700, Applied Biosystems). PCR products were run in $0.8 \%$ agarose gel, stained with ethidium bromide and then visualized using an Image Analyzer Gel Doc (Biorad). Purification was performed using a QIaquick Gel Extraction Kit (Qiagen) and DNA sequencing on both strands was performed by the dideoxy chain termination method with an ABI Prism 3730XL DNA analyzer, using the ABI Prism BigDye terminator cycle sequencing ready reactions kit (PE Biosystems) according to the manufacturer's protocol.

\section{Phylogenetic analyses}

$16 \mathrm{~S}$ rRNA and $g y r B$ gene sequences were aligned using the CLUSTAL W software, version 1.7 (Thompson et al., 1994), and corrected manually. Phylogenetic analyses were performed using the neighbor-joining (NJ) (Saitou \& Nei, 1987) method. A phylogenetic tree was generated from the NJ method for 16S rRNA gene sequences and the stability of the tree was assessed by bootstrap analysis with the resampling method of Felsenstein (1993) with 1000 replications using DNAMAN, version 4.03 (Lynnon BioSoft). The nucleotide sequences reported in this paper have been deposited in GenBank under accession numbers AY741363, AY741364, EF527810, EU183543, EU126969 and EU126970.

\section{Copper resistance assays}

One hundred microliters of spore suspensions $\left(1 \times 10^{9} \mathrm{CFU} \mathrm{mL}^{-1}\right)$ of each strain, prepared as described before (Albarracín et al., 2005), were inoculated in cultures of tripticase-soy-broth (Britania). The cultures were incubated at $30^{\circ} \mathrm{C}$ for 4 days in an orbital shaker at 100 r.p.m. Cells were collected by centrifugation at $3000 \mathrm{~g}$ for $10 \mathrm{~min}$ at $4{ }^{\circ} \mathrm{C}$ and washed twice with distilled water. The resulting 
pellet of vegetative cells was inoculated in batch cultures $(15 \mathrm{~mL})$ of minimal medium (MM in g: L-asparagine, 0.5; $\mathrm{K}_{2} \mathrm{HPO}_{4}, 0.5 ; \mathrm{MgSO}_{4} \cdot 7 \mathrm{H}_{2} \mathrm{O}, 0.2 ; \mathrm{FeSO}_{4} \cdot 7 \mathrm{H}_{2} \mathrm{O}, 0.01$; and glucose, 10.0; per liter; supplemented with $\mathrm{CuSO}_{4}$ $0.5 \mathrm{mM}$ and $\mathrm{pH} 7$ ) in order to obtain a final concentration of $0.1 \mathrm{~g}$ dry biomass $\mathrm{L}^{-1}$. Cultures without copper were used as controls. The cultures were incubated under the same conditions as described before and samples were collected after 3, 5 and 7 days of growth. The cells were centrifuged at $3000 \mathrm{~g}$ for $10 \mathrm{~min}$ at $4{ }^{\circ} \mathrm{C}$ and washed twice with distilled water. The resulting cell pellet was dried at $105^{\circ} \mathrm{C}$ until a constant weight for biomass determination. All assays were performed in duplicate.

\section{Copper determination}

Copper concentration in the free cell supernatant was analyzed using a modified procedure of the colorimetric technique using bicinchoninic acid reagent (BAC; Anwar et al., 2000). This technique was originally optimized for detection of copper ions in bacterial leachates of large volumes $(25 \mathrm{~mL})$; in this work, a miniprep procedure was adapted as follows: $100 \mu \mathrm{L}$ of sample from the supernatant and $1100 \mu \mathrm{L}$ of distilled water were mixed with $200 \mu \mathrm{L}$ of $10 \%$ hidroxilamine solution (Sigma Chemical), which allowed the reduction of $\mathrm{Cu}^{2+}$ to $\mathrm{Cu}^{1+}$. One thousand microliters of tartrate buffer $(0.5 \mathrm{M}$ sodium tartrate $\mathrm{HCl}$; $\mathrm{pH}$ 5.5) was added to the previous mix to maintain the optimum $\mathrm{pH}$ for the colorimetric reaction. Immediately after this, $100 \mu \mathrm{L}$ of BAC $(0.1 \%)$ was added to the mixture to allow $\mathrm{Cu}^{1+}$ ions to bind to this reagent, thus generating a colorimetric reaction $(\lambda=560 \mathrm{~nm})$. After $10 \mathrm{~min}$ at room temperature, aliquots of $250 \mu \mathrm{L}$ were taken from the final mixture and were read in an ELISA Beckman CoulterAD200. All assays were performed in triplicate. The validity of the BAC method for determining $\mathrm{Cu}^{1+}$ was established previously by its comparison with the atomic absorption spectroscopic method and it was found that copper determinations by both methods were very close and comparable within reasonable precision limits (Anwar et al., 2000).

\section{Cupric reductase}

The cupric reductase assay was developed from a method described previously for yeast and algae cupric reductase (Hassett \& Kosman, 1995; Hill et al., 1996) with modifications to accommodate the growth conditions of the Streptomyces strains and to use the $\mathrm{Cu}$ (I)-BAC colorimetric method (Anwar et al., 2000). Cells from copper-deficient or copper-supplemented $\left(\mathrm{MM} \mathrm{CuSO}_{4} 0.5 \mathrm{mM}\right)$ cultures in logphase growth were collected by centrifugation $(3000 \mathrm{~g}$, $5 \mathrm{~min}$ ), washed and resuspended in distilled water. Copper sulfate (chelated with an equimolar amount of EDTA) and BAC were added from neutral stock solutions to final concentrations of $0.5 \mathrm{mM}$ and $0.008 \%$, respectively. The cells were returned to the growth chamber $\left(30^{\circ} \mathrm{C}\right.$, 100 r.p.m.) and incubated for $60 \mathrm{~min}$. After that, cells were collected by centrifugation and the $\mathrm{Cu}$ (I) amount formed was determined by measuring the absorbance of the $\mathrm{Cu}$ (I)BAC complex at $560 \mathrm{~nm}$ (Anwar et al., 2000). The resulting cell pellet was dried at $105^{\circ} \mathrm{C}$ until a constant weight for biomass determination. All assays were performed in triplicate. Control experiments verified that product formation was dependent on the inclusion of $\mathrm{Cu}$ (II), BCA and cells in the assay.

\section{Statistical analyses}

Statistical analyses were conducted using the MICROCAL ${ }^{\text {TM }}$ ORIGIN Working Model Version 6.0. A paired $t$-test and variance analysis were used with a probability level of $P<0.05$.

\section{Results and discussion}

\section{Morphological, physiological and molecular characterization of the actinomycete strains}

The morphological characteristics of isolates $\mathrm{AB} 2 \mathrm{~A}, \mathrm{AB} 3$ and AB5A were consistent with its assignment to the genus Streptomyces (Williams et al., 1989). All isolates form a highly branched substrate mycelium and aerial hyphae, which carries smooth (AB2A and AB3) or rugose (AB5A)surfaced spores in spiral chains. All isolates grew well on ISP 4 and ISP 7, but poorly on ISP 6. AB2A and AB5A strains grew well on ISP 5 although strain $\mathrm{AB} 3$ was not able to grow on this medium. API tests indicated a very different enzymatic profile among the isolates, indicating that they could be different strains. The differences in morphology, carbohydrate assimilation, $\mathrm{pH}$ and temperature tolerance observed among them confirmed this hypothesis. None of the tested strains produced diffusible pigments on any tested media.

The assignment of the three strains to the genus Streptomyces was also supported by $16 \mathrm{~S}$ rRNA and gyrB gene sequence data. Comparison of the almost complete $16 \mathrm{~S}$ rRNA gene sequence of the tested strains with corresponding streptomycete sequences from the GenBank database showed that all three strains lay in the evolutionary clade of Streptomyces violaceusniger allied taxa (Fig. 1). A high similarity value (higher than 99\%) has been observed among the 16S rRNA gene sequences of all our strains and those of the members of the S. violaceusniger clade (Williams et al., 1983, 1989). Previous works have shown that the Streptomyces genus is underspeciated and polyphasic approaches have been used to describe novel species (Zhang et al., 2003). High nucleotide similarities have been reported for several validly described species belonging to the 


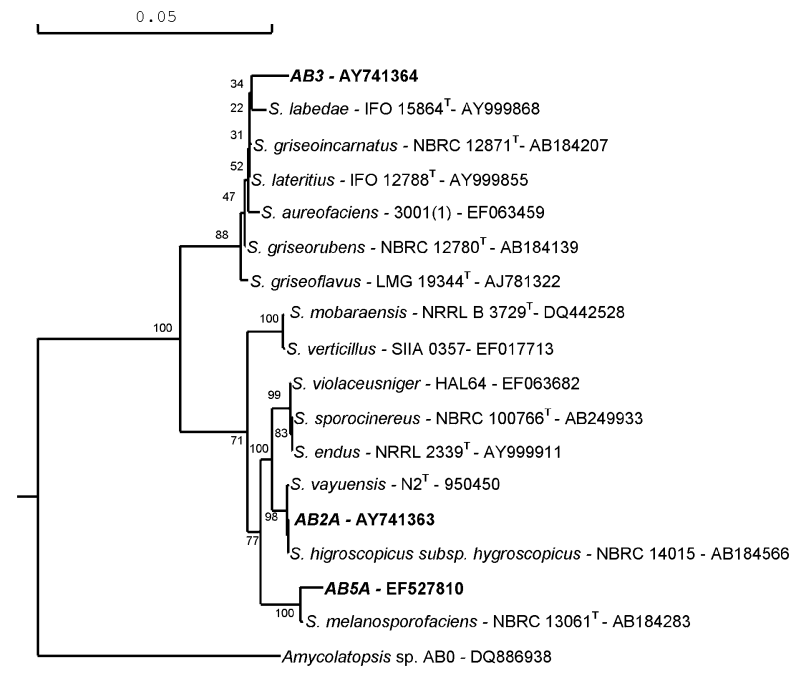

Fig. 1. Phylogenetic tree for $16 S$ rRNA gene sequences of $A B 2 A, A B 3$ and $A B 5 A$ strains and representatives of the Streptomyces genus available in the database. It was constructed using the NJ method (Saitou \& Nei, 1987) and the stability of the tree was assessed by bootstrap analysis with the resampling method of Felsenstein (1993) with 1000 replications, using DNAMAN, version 4.03 (Lynnon BioSoft). Amycolatopsis sp. AB0 (Albarracín et al., 2008) was considered as the outgroup.

S. violaceusniger clade. For instance, a divergence sequence of $2.70 \%$ was found between the recently described Streptomyces yunnanensis sp. nov. (YIM $41004^{\mathrm{T}}$ ), Streptomyces hygroscopicus and S. violaceusniger (type strains) (Zhang et al., 2003). In addition, $16 \mathrm{~S}$ rRNA gene comparison showed that strains $\mathrm{AB} 2 \mathrm{~A}$ and $\mathrm{AB} 5 \mathrm{~A}$ were more closely related to each other ( $96.5 \%$ of similarity) than any of them with the AB3 strain ( $94 \%$ of similarity).

Phylogenetic analysis of partial sequences of the $g y r B$ gene, which encodes the B subunit of DNA gyrase, has been used for the classification of several types of bacteria and it has been shown to be a useful tool for discrimination at the species level (Hatano et al., 2003). Recently, a good correlation between gyrB sequence similarity values and levels of DNA-DNA relatedness has been reported in whorl-forming Streptomyces species; all strains that exhibited 98.5-100\% gyrB sequence similarity showed almost identical phenotypes and high DNA-DNA relatedness (70-100\%) (Hatano et al., 2003).

Gyrase B sequences analyses of our strains, and their comparison with sequences available in the database, indicate a great similarity to previously described Streptomyces gyrB sequences, supporting the statement that they belong to the Streptomyces genus. Strain AB2A (accession number: EU126969) showed a close similarity to Streptomyces thioluteus (92\%; accession number: AB072887), Streptomyces aspergilloides (90\%; accession number: AB072833) and Streptomyces morookaensis (90\%; accession number: AB072867) gyrB genes. Strain AB3 (accession number:
EU183543) showed a $92 \%$ and $91 \%$ similarities to Streptomyces coelicolor (accession number: L27063) and Streptomyces pallidus (accession number: AB072874), respectively, while strain AB5A (accession number: EU126970) was most closely related to S. thioluteus (97\%; accession number: $\mathrm{AB} 072887)$ and S. aspergilloides (96\%; accession number: $\mathrm{AB} 072833)$. It was noted that the database is very incomplete with respect to this molecular marker for Streptomyces comparisons. It was not possible to confirm the phylogenetic relationship established upon the $16 \mathrm{~S}$ rRNA gene marker, because the corresponding sequences for GyrB proteins have not yet been published. Therefore, our work constitutes a contribution towards increasing the reports for Streptomyces gyrB sequences in the database.

\section{Time-course of growth and copper removal}

Copper resistance in Actinobacteria has scarcely been studied and most of the previous reports deal solely with strain isolation and the description of their copper resistance levels assessed in agar media (Schmidt et al., 2005; Abou-Shanab et al., 2007). Therefore, accurate information on copper removal processes and growth kinetics is needed to develop bioremediation strategies for polluted soils and effluents. Given the great potential of Streptomyces strains as sources of novel copper-binding compounds (Kothe et al., 2005), we decided to study the growth and copper removal ability of three copper-resistant strains belonging to this genus.

The results obtained from the effect of initial copper ion concentration on the $\mathrm{MM}$ growth $\left(\mathrm{MM}_{\mathrm{Cu}}\right)$ of the selected strains were given as the biomass obtained (dry weight) at 3 , 5 and 7 days and residual copper in the supernatant (\% of initial metal content) measured at similar times. Different patterns of growth and copper removal from the $\mathrm{MM}_{\mathrm{Cu}}$ were observed for all the Streptomyces strains (Fig. 2). Approximately $80 \%$ of initial copper within the $\mathrm{MM}_{\mathrm{Cu}}$ was depleted after $72 \mathrm{~h}$ of growth by Streptomyces sp. AB2A (Fig. $2 \mathrm{a})$, in accordance with a fourfold increase in its biomass. This removal efficiency could be compared with the ones reported for other Gram-positive bacteria. Hassen et al. (1998) reported a Bacillus thuringiensis strain capable of producing $34 \%$ copper removal from a medium supplemented with $30 \mathrm{mg} \mathrm{L}^{-1}$, while Amoroso et al. (2001) and Albarracín et al. (2008) reported for Streptomyces sp. R25 and Amycolatopsis sp. AB0 a copper removal efficiency of $50 \%$ and $70 \%$, respectively, in MM supplemented with $32 \mathrm{mg} \mathrm{L}^{-1}$ of $\mathrm{Cu}^{2+}$. Another actinobacterium, Nocardia amarae, was used to improve the bioremediation efficiency of an active sludge; in this case, $25 \%$ removal of copper from the sludge containing $10 \mathrm{mg}$ copper $\mathrm{L}^{-1}$ was observed (Kim et al., 2002).

An increase in copper bioavailability was observed in the AB2A growth course after $144 \mathrm{~h}$ (Fig. 2a). It is possible that 

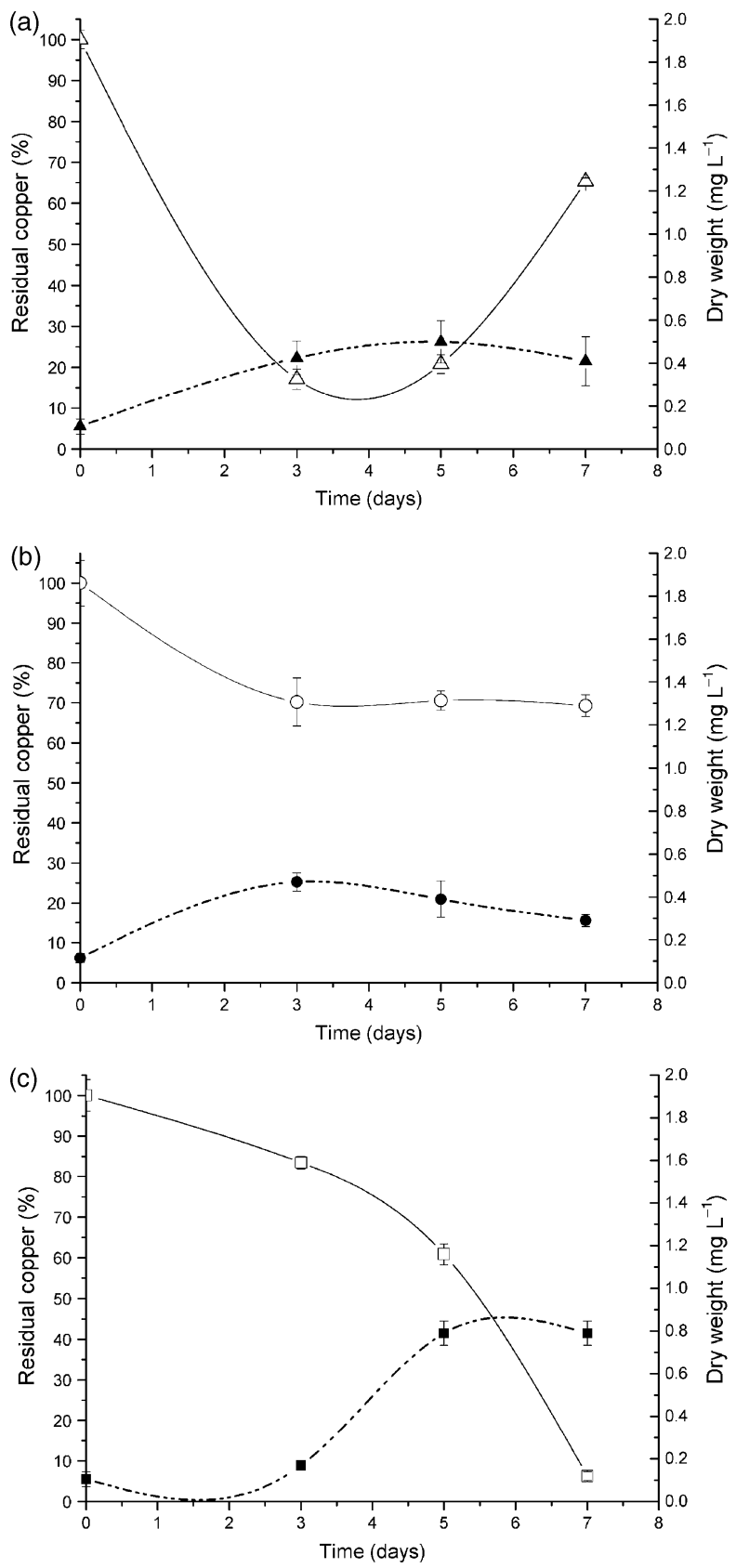

Fig. 2. Effect of copper on the growth of Streptomyces sp. AB2A $(-\mathbf{\Delta}-), \mathrm{AB} 3(--)$ and $\mathrm{AB} 5(-\mathbf{-}-)$ strains expressed as dry weight in $\mathrm{MM}$ added with $0.5 \mathrm{mM} \mathrm{CuSO}_{4}$ (total copper: $31.22 \mathrm{mg} \mathrm{L}^{-1}$ ). Residual copper was measured in the supernatant using the colorimetric method based on the BCA method at similar times: $(-\triangle-)$ for AB2A, (-O-) for $A B 3$ and ( $-\square-)$ for $A B 5 A$. The points represent the average of duplicates, and error bars indicate \pm SDs of the means. Error bars smaller than the symbols are not shown.

in an early stage the copper was allowed to enter into the cell for physiological requirements of this microorganism, but soon after, when the metal reached toxic levels, it might have induced an efflux mechanism. This behavior has been well documented in other copper-resistant microorganisms such as Pseudomonas syringae (Arnesano et al., 2003), Escherichia coli (Franke et al., 2003) and Enterococcus hirae (Solioz \& Stoyanov, 2003).

In contrast, Streptomyces sp. AB3 and AB5A had only copper retention phenotypes under the same culture conditions as there was no evidence of an increase in copper availability after 7 days of growth (Fig. 2b and c). Streptomyces sp. AB3 demonstrated a fourfold increase in its biomass during the first $72 \mathrm{~h}$, which concurred with the main copper removal from $\mathrm{MM}_{\mathrm{Cu}}$ (c. 30\%). Towards the end of the assay, AB3 strain biomass slightly diminished while the copper residual concentration in the supernatant did not change (Fig. 2b). This phenomenon may be due to the known capability of Streptomyces strains of producing resistant spores (Kothe et al., 2005) that may allow the microorganism to retain the copper within the cell in spite of biomass reduction. This property has great potential for utilization in bioremediation strategies (Amoroso et al., 2001; Polti et al., 2007). An interesting pattern was observed in response to copper stress by Streptomyces sp. AB5A (Fig. 2c). During the first 3 days of culture, no significant increases in biomass or significant copper removal were observed. Between day 3 and 5, an eightfold increase of biomass along with $25 \%$ of copper removal from $\mathrm{MM}_{\mathrm{Cu}}$ was found while the most important copper removal percentage (65\%) was observed in the stationary phase of growth (Fig. 2c). This behavior may correspond to a biphasic uptake of metals: (1) initial phase of biosorption, where copper removal from $\mathrm{MM}_{\mathrm{Cu}}$ was more related to physico-chemical sorption to biomass (3-5 days), followed by (2) a probable metabolismdependent active uptake of metals (5-7 days) as has been reported for other microorganisms (Malik, 2004; Albarracín et al., 2008).

\section{Extracelullar cupric reductase activity}

During the incubation time of the selected strains, modifications of oxidation states of copper $\left(\mathrm{Cu}^{1+} / \mathrm{Cu}^{2+}\right.$ balance) in the culture supernatant were observed (data not shown), which may indicate an active mechanism of copper reduction at the cell surface. Current evidence suggests that $\mathrm{Cu}$ (I) is the form that is taken up by cells and transported intracellularly (Solioz \& Stoyanov, 2003). In order to assess whether there is any copper reductase activity involved in the copper homeostatic process of our Streptomyces sp. strains, we adapted a technique to reveal $\mathrm{Cu}$ (I) formation using the BCA method.

Streptomyces sp. AB2A, AB3 and AB5A showed cupric reductase activity $\left(\mathrm{RA}_{\mathrm{Cu}}\right)$ under both conditions, when cells were preadapted (AC) or not (NAC) to copper (Fig. 3). Interestingly, levels of $\mathrm{RA}_{\mathrm{Cu}}$ in $\mathrm{AC}$ of all strains concurred with their copper removal efficiency (Fig. 2); Streptomyces 
sp. AB5A, which depicted the major removal efficiency (95\%) had the optimal $\mathrm{RA}_{\mathrm{Cu}}[100 \%$ of $\mathrm{Cu}$ (II) reduction after $60 \mathrm{~min}$ ] (Fig. 3). Streptomyces sp. AB2A, which removed $80 \%$ of copper from $\mathrm{MM}_{\mathrm{Cu}}$ (Fig. 2a), reduced $93 \%$ of $\mathrm{Cu}$ (II) after $60 \mathrm{~min}$ (Fig. 3), while Streptomyces sp. AB3, which removed $30 \%$ of copper from the $\mathrm{MM}_{\mathrm{Cu}}$ (Fig. 2b), only reduced $14 \%$ of total copper after 60 min of incubation (Fig. 3). Extracellular copper reductase activities were observed before in E. hirae (Solioz \& Stoyanov, 2003), yeast (Hassett \& Kosman, 1995), green algae (Hill et al., 1996) and even plants (Solioz \& Stoyanov, 2003). In E. coli, it was shown that the $\mathrm{Cu}$ (II) ions that enter the periplasm can be reduced to $\mathrm{Cu}$ (I) by the reductase $\mathrm{NDH}-2$ (Rapisarda et al., 2002). Fan \& Rosen (2002) studied Cop A, a Cu (I)translocating P-type ATPase of E. coli that allows the bacteria to expel $\mathrm{Cu}$ (I) from the periplasm and avoid its toxicity. More recently, CopC, an intriguing copper trafficking periplasmic protein that binds $\mathrm{Cu}$ (I) and $\mathrm{Cu}$ (II) at different sites, was described in P. syringae (Arnesano et al., 2003).

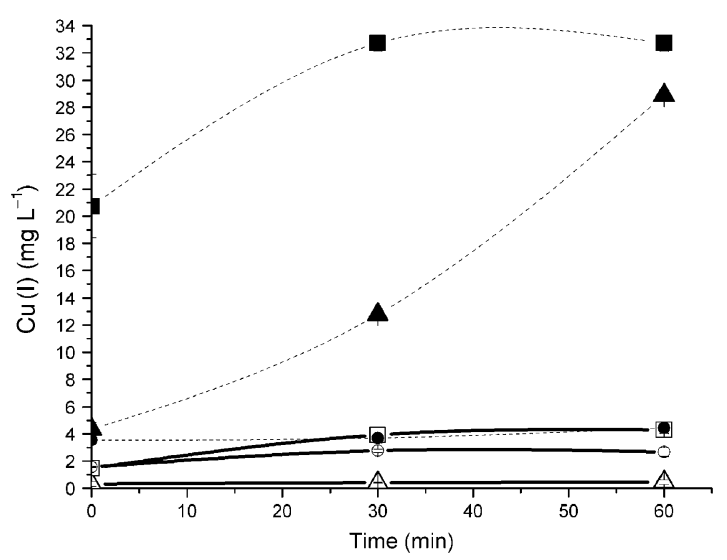

Fig. 3. $C u(I)$ formation by log-phase cultures of $A C$ and NAC Streptomyces sp. AB2A, AB3 and AB5A upon addition of $\mathrm{Cu}$ (II)-EDTA complexes $\left(31.22 \mathrm{mg} \mathrm{L}^{-1}\right)$ to $2.5 \mathrm{~mL}$ of water containing $\mathrm{BCA}(0.008 \%)$. Mean values of triplicates and the SDs are indicated. Error bars smaller than the symbols are not shown. Symbols and lines, copper preadapted cells (AC) of the AB2A strain (- - ); nonpreadapted cells (NAC) of the $A B 2 A$ strain $(-\triangle-) ; A C$ of the $A B 3$ strain (- - - ); NAC of the $A B 3$ strain (-O-); $A C$ of the AB5A strain (- - ) and NAC of the AB5A strain (- $\square-)$.
Any kind of these mechanisms may be presented on the cell surface of our Streptomyces sp. strains, which will explain their copper reductase activities.

On the other hand, NAC of all strains showed lower $\mathrm{RA}_{\mathrm{Cu}}$ (Table 1). The cupric reductase activity in NAC of AB2A, $A B 3$ and $A B 5$ strains was $0.77 \%, 29 \%$ and $5.46 \%$ of $\mathrm{RA}_{\mathrm{Cu}}$ in AC, respectively (Table 1). Streptomyces sp. AB5A demonstrated the highest $\mathrm{RA}_{\mathrm{Cu}}$ in both $\mathrm{AC}$ and NAC. In Chlamydomonas reinhardtii (Hill et al., 1996) and yeasts (Hassett \& Kosman, 1995), the cupric reductase activity is increased in copper-deficient cultures compared with copper-sufficient cells, which suggests that it is a component of the copper assimilation pathway. In our Streptomyces strains, we found the opposite effect, which may indicate that the copper reduction process is more related to an inducible copper resistance mechanism. As $\mathrm{Cu}$ (II) reduction is always associated with $\mathrm{Cu}$ (II) uptake, we think that it may also trigger some enzymatic processes in the intracellular environment to cope with the copper accumulation within the cell. Further research is being conducted to clarify this mechanism by studying the mRNA and proteomic profiles of copper-deficient and copper-adapted cells.

\section{Conclusions}

Both genotypic and phenotypic data supported the assignment of the selected strains $\mathrm{AB} 2 \mathrm{~A}, \mathrm{AB} 3$ and $\mathrm{AB} 5 \mathrm{~A}$ to the genus Streptomyces. Their physiological, morphological and molecular characteristics plus their distinctive copper resistance phenotypes revealed considerable divergence among the isolates.

Highly dissimilar growth patterns and copper removal efficiency from $\mathrm{MM}_{\mathrm{Cu}}$ were observed for the selected Streptomyces sp. Strain AB2A showed an early mechanism of copper uptake/retention ( $80 \%$ until day 3$)$, followed by a drastic metal efflux process (5-7 day). In contrast, Streptomyces sp. AB3 and AB5A only showed copper retention phenotypes under the same culture conditions. Particularly, Streptomyces sp. AB5A showed the best efficiency in copper removal (94\%), although a longer lag phase was observed for this microorganism in $\mathrm{MM}_{\mathrm{Cu}}$.

Cupric reductase activity was detected in both copperadapted cells and nonadapted cells of all three strains but

Table 1. Cupric reductase activity of log-phase cultures of $A C$ and NAC Streptomyces sp. AB2A, AB3 and AB5A measured after 60 min of incubation of the cells with $\mathrm{Cu}$ (II)-EDTA complexes $\left(31.22 \mathrm{mg} \mathrm{L}^{-1}\right)$ added to $2.5 \mathrm{~mL}$ of water containing BCA $(0.008 \%)$

\begin{tabular}{|c|c|c|c|}
\hline \multirow[b]{2}{*}{ Conditions of cultures } & \multicolumn{3}{|l|}{ Strains } \\
\hline & $\mathrm{AB} 2 \mathrm{~A}$ & AB3 & AB5A \\
\hline \multicolumn{4}{|c|}{ Activity \pm SD $\left(\mu \mathrm{g}\right.$ copper $\mathrm{mg}^{-1}$ cells $\mathrm{min}^{-1}$ ) } \\
\hline Cells grown in $\mathrm{MM}_{\mathrm{Cu}}(\mathrm{AC})$ & $2.61( \pm 0.01)$ & $0.62( \pm 0.09)$ & $8.06( \pm 1.45)$ \\
\hline Cells grown in MM (NAC) & $0.02( \pm 0.01)$ & $0.18( \pm 0.04)$ & $0.44( \pm 0.14)$ \\
\hline
\end{tabular}

The enzymatic activity was expressed as $\mu \mathrm{g}$ copper $\mathrm{mg}^{-1}$ cells $\mathrm{min}^{-1}$. Mean values of triplicates and the SDs are indicated. 
this activity was up to 100 -fold higher in preadapted cells of Streptomyces sp. AB2A. This cupric reductase activity may be directly related to the copper uptake process and hence is an important part of the copper-resistant mechanism. This work is the first report of extracellular cupric reductase activity present in Actinobacteria and within the genus Streptomyces.

Based on the results presented, we proposed Streptomyces sp. AB5A as a potential useful tool for performing efficient bioremediation processes of copper-polluted soils or effluents.

\section{Acknowledgements}

This work was supported by CIUNT, FONCyT, and CONICET, Argentina. Dr V.H.A. was supported by a CONICET doctoral scholarship and A.L.A. was supported by a CIUNT graduate student scholarship. The authors gratefully acknowledge the assistance of Mr Guillermo Borchia.

\section{References}

Abbas A \& Edwards C (1990) Effects of metals on Streptomyces coelicolor growth and actinorhodin production. Appl Environ Microbiol 56: 675-680.

Abou-Shanab RAI, van Berkum P \& Angle JS (2007) Heavy metal resistance and genotypic analysis of metal resistance genes in gram-positive and gram-negative bacteria present in Ni-rich serpentine soil and in the rhizosphere of Alyssum murale. Chemosphere 68: 360-367.

Albarracín VH, Benito JM, Siñeriz Louis M, Amoroso MJ \& Abate CM (2004) Identification of copper resistant microorganisms by PCR. Environmental Microbiology Methods and Protocols, Series "Methods in Biotechnology" (Spencer JFT \& Ragout Spencer A, eds), pp. 243-248. Humana Press Inc, New Jersey.

Albarracín VH, Amoroso MJ \& Abate CM (2005) Isolation and characterization of indigenous copper resistant actinomycete strains. Chemie Erde-Geochem 65: 145-156.

Albarracín VH, Winik B, Kothe E, Amoroso MJ \& Abate CM (2008) Copper bioaccumulation by the actinobacterium Amycolatopsis sp. AB0. J Basic Microbiol, in press. DOI: 10.1002/jobm.200700360.

Amoroso MJ, Castro GR, Durán A, Peraud O, Oliver G \& Hill RT (2001) Chromium accumulation by two Streptomyces spp. isolated from riverine sediments. J Ind Microbiol Biotechnol 24: 210-215.

Anwar MA, Iqbal M, Qamar MA, Rehman M \& Khalid AM (2000) Technical communication: determination of cuprous ions in bacterial leachates and for environmental monitoring. World J Microbiol Biotechnol 16: 135-138.

Arnesano F, Banci L, Bertini I, Mangani S \& Thompsett AR (2003) A redox switch in CopC: an intriguing copper trafficking protein that binds copper (I) and copper (II) at different sites. Proc Natl Acad Sci 100: 3814-3819.
Calcutt MJ (1994) Gene organization in the dnaA-gyrA region of the Streptomyces coelicolor chromosome. Gene 151: 23-28.

Fan B \& Rosen BP (2002) Biochemical characterization of CopA, the Escherichia coli $\mathrm{Cu}(\mathrm{I})$-translocating P-type ATPase. J Biol Chem 277: 46987-46992.

Felsenstein J (1993) PHYLIP (Phylogeny Inference Package) Version 3.5c. Department of Genetics, University of Washington, Seattle.

Franke S, Grass G, Rensing C \& Nies DH (2003) Molecular analysis of the copper-transporting efflux system CusCFBA of Escherichia coli. J Bacteriol 185: 3804-3812.

Georgopoulus PG, Roy A, Opiekun RE, Yonone-Lioyand MJ \& Lioy PJ (2002) Introduction: copper and man. Environmental Dynamics and Human Exposure to Copper (Georgopoulus PG, Roy A, Opiekun RE, Yonone-Lioyand MJ \& Lioy PJ, eds), pp. 15-26. International Copper Association Ltd, New York.

Hassen A, Saidi N, Cherif M \& Boudabous A (1998) Effects of heavy metals on Pseudomonas aeruginosa and Bacillus thuringiensis. Bioresour Technol 65: 73-82.

Hassett R \& Kosman DJ (1995) Evidence for Cu (II) reduction as a component of copper uptake by Saccharomyces cerevisiae. J Biol Chem 270: 128-134.

Hatano K, Nishii T \& Kasai H (2003) Taxonomic re-evaluation of whorl-forming Streptomyces (formerly Streptoverticillium) species by using phenotypes, DNA-DNA hybridization and sequences of gyrB, and proposal of Streptomyces luteireticuli (ex Katoh and Arai 1957) corrig., sp. nov., nom. rev. Int J Syst Evol Microbiol 53: 1519-1529.

Heuer H, Krsek M, Baker P, Smalla K \& Wellington EM (1997) Analysis of actinomycete communities by specific amplification of genes encoding $16 \mathrm{~S}$ rRNA and gelelectrophoretic separation in denaturing gradients. Appl Environ Microbiol 63: 3233-3241.

Hill K, Hassett R, Kosman D \& Merchant S (1996) Regulated copper uptake in Chlamydomonas reinhardtii in response to copper availability. Plant Physiol 112: 697-704.

Kim DW, Cha DK, Wang J \& Huang CP (2002) Heavy metal removal by activated sludge: influence of Nocardia amarae. Chemosphere 46: 137-142.

Kothe E, Bergmann H \& Büchel G (2005) Molecular mechanisms in bio-geo-interactions: from a case study to general mechanisms. Chemie Erde-Geochem 65: 7-27.

Malik A (2004) Metal bioremediation through growing cells. Environ Int 30: 261-278.

Polti MA, Amoroso MJ \& Abate CM (2007) Chromium (VI) resistance and removal by actinomycete strains isolated from sediments. Chemosphere 67: 660-667.

Rapisarda VA, Chehin RN, De Las RJ, Rodriguez-Montelongo L, Farias RN \& Massa EM (2002) Evidence for Cu(I)-thiolate ligation and prediction of a putative copper-binding site in the Escherichia coli NADH dehydrogenase-2. Arch Biochem Biophys 405: 87-94.

Ravel J, Amoroso MJ, Colwell RR \& Hill RT (1998) Mercury resistant actinomycetes from Chesapeake Bay. FEMS Microbiol Lett 162: 177-184. 
Saitou N \& Nei M (1987) The neighbor-joining method: a new method for reconstructing phylogenetic trees. Mol Biol Evol 4: 406-425.

Schmidt A, Haferburg G, Siñeriz M, Merten D, Buchel G \& Kothe E (2005) Heavy metal resistance mechanisms in actinobacteria for survival in AMD contaminated soils. Chemie ErdeGeochem 65: 131-144.

Shirling EB \& Gottlieb D (1966) Methods for characterization of Streptomyces species. Int J Syst Bacteriol 16: 313-340.

Silver S \& Phung LT (1996) Bacterial heavy metal resistance: new surprises. Ann Rev Microbiol 50: 753-789.

Solioz M \& Stoyanov JV (2003) Copper homeostasis in Enterococcus hirae. FEMS Microbiol Rev 27: 183-195.

Thompson JD, Higgins D \& Gibson TJ (1994) CLUSTAL W: improving the sensitivity of progressive multiple sequence alignment through sequence weighting, position-specific gap penalties and weight matrix choice. Nucleic Acids Res 22: 4673-4680.

Wink JM, Kroppenstedt RM \& Ganguli BN (2003) Three new antibiotic producing species of the genus Amycolatopsis,
Amycolatopsis balhimycina sp. nov., A. tolypomycina sp. nov., A. vancoresmycina sp. nov., and description of Amycolatopsis keratiniphila subsp. keratiniphila subsp. nov. and $A$.

keratiniphila subsp. nogabecina subsp. nov. Syst Appl Microbiol 26: $38-46$.

Williams ST, Lanning S \& Wellington EMH (1983) Ecology of Actinomycetes. The Biology of Actinomycetes (Goodfellow M, ed), pp. 481-527. Academic Press, London.

Williams ST, Goodfellow M \& Alderson G (1989) Genus Streptomyces Waksman and Henrici 1943. Bergey's Manual of Systematic Becteriology, Vol. 4. (Williams ST, Sharpe ME \& Holt JG, eds), pp. 2452-2492. Williams and Wilkins, Baltimore.

Yamamoto S \& Harayama S (1995) PCR amplification and direct sequencing of gyrB genes with universal primers and their application to the detection and taxonomic analysis of Pseudomonas putida strains. Appl Environ Microbiol 61: 3768.

Zhang Q, Li W-J, Cui X-L, Li M-G, Xu L-H \& Jiang C-L (2003) Streptomyces yunnanensis sp. nov., a mesophile from soils in Yunnan, China. Int J Syst Evol Microbiol 53: 217-221. 